\title{
LOS HISTORIADORES MEXICANOS DEL SIGLO XIX Y EL SURGIMIENTO DE LA IDENTIDAD NACIONAL MEXICANA
}

\author{
Jerzy Achmatowicz \\ Universidad de Wroclaw \\ Polonia \\ ibero_2005@wp.pl
}

doi.org/10.15452/SR.2020.20.0007

\begin{abstract}
Resumen. El presente artículo está tratando de encontrar y vincular el quehacer de la historiografía mexicana del siglo XIX con el surgimiento de la identidad nacional de la sociedad de México. Contextualizando este proceso se recuerdan los principales acontecimientos de la escena política de un país recién independiente y soberano, involucrado también en toda una serie de conflictos internacionales. Se ha intentado encontrar en las obras de Teresa de Mier, de Bustamante, Ramírez, Icazbalceta, Paso y Troncoso, Alemán, Orozco y Berra aquellos aportes que tuvieron un impacto relevante en la visión del pasado histórico relacionado tanto con el proceso independentista como con la historia prehispánica, o sea, mesoamericana y colonial. Dichos aportes se perciben principalmente en el rescate de la obra maestra de Fray Bernardino de Sahagún y la confrontación con la narración fundacional tanto de la cultura criolla como cultura indígena que se formaba después de la conquista, es decir, lo que se conoce como milagrosa aparición de la Virgen de Guadalupe.
\end{abstract}

Palabras clave. Sahagún. Icazbalceta. Bustamante. Historiografía mexicana. Identidad nacional.

Abstract. The Mexican Historians of the $19^{\text {th }}$ Century and the Rising of the Mexican National Identity. The present article is trying to find and link the work of the $19^{\text {th }}$-century Mexican historiography with the emergence of the national identity of the society of Mexico. Contextualizing this process, the paper recalls the main events of the political scene of a newly independent and sovereign country, also involved in a whole series of international conflicts. The purpose is to find, in the works of Teresa de Mier, Bustamante, Ramírez, Icazbalceta, Paso and Troncoso, Alemán, Orozco and Berra, those contributions that had a relevant impact on 
the vision of the historical past related to both the independence process and the pre-Hispanic period, that is, Mesoamerican and colonial history. These contributions are perceived mainly in the rescue of the masterpiece of Fray Bernardino de Sahagún and the confrontation with the foundational narration of both the Creole culture and the indigenous culture that was formed after the conquest, i.e. the miraculous appearance of the Virgin from Guadalupe.

Keywords. Sahagún. Icazbalceta. Bustamante. Mexican Historiography. National Identity. 


\section{Introducción}

A título de palabras introductorias recordemos una invocatoria de Icazbalceta, quien decía al enterarse de que un estadounidense acababa de escribir una historia sobre México: «...eso lo tenemos que hacer nosotros mismos y por eso hay que recuperar las fuentes para que los historiadores mexicanos escriban su propia historia». En la presente publicación nos vamos a dedicar principalmente a tales figuras de la historiografía mexicana del siglo XIX como: Fray Servando Teresa de Mier, Carlos María Bustamante, José Fernando Ramírez, el mencionado Joaquín García Icazbalceta y, un poco de paso, a Manuel Orozco y Berra, y Francisco del Paso y Troncoso. Todos ellos prácticamente después de la independencia de México bien asentada participaron en un movimiento intelectual, particular y excepcional, es decir, crearon una necesidad y respondieron a ella en cuanto a la búsqueda y rescate del acervo cultural prehispánico y colonial temprano en el contexto del surgimiento de la autoconciencia nacional mexicana. Vamos a abordar principalmente dos procesos. Primero, el rescate de la obra gigantesca de Fray Bernardino de Sahagún y segundo, lo de la revitalización del debate en torno a las apariciones guadalupanas, es decir, una confrontación entre el aporte de Carlos María de Bustamante y su severa crítica de parte de Icazbalceta. Por cierto, en ambos casos trataremos de contextualizarlos de la manera más amplia posible.

Después de las turbulencias de 1810-1823, con conflictos internos marcados por personajes tales como Vicente Guerrero, Santa Ana y otros, turbulencias reformatorias de los tiempos de Juárez, intervenciones extranjeras: la estadounidense (que supuso la pérdida de la mitad del territorio nacional: en 1847), la española y finalmente la francesa, con la instalación del segundo Imperio de Maximiliano de Habsburgo y la restauración de la República en 1867, se abre el espacio para la ferviente búsqueda de la materia prima para forjar de a poco la autoconciencia y autosaber de la nación mexicana. Este espacio histórico lo vamos a dividir por las necesidades de nuestra comunicación en dos periodos: el que finalizaba en 1848 con el deceso de Carlos María de Bustamante y el otro, que finalizaba en 1894 junto con la partida de Joaquín García Icazbalceta.

\section{Sobre dos periodos de la historiografía mexicana en el siglo XIX}

Respecto al primer periodo leemos lo siguiente:

Durante 1824-1855 desfilaron por el poder cuarenta y cinco administraciones presidenciales definitivas o interinas, durando cada una, en promedio, ocho meses. Al mismo tiempo se produjeron alrededor de cien pronunciamientos, motines y rebeliones, aproximadamente una cada cuatro meses. Santa Anna dirigió al país en once ocasiones, cinco veces como liberal y seis como conservador. Se ensayaron tres distintas constituciones y tipos de regímenes gubernamentales, uno liberal y dos centralistas. El país sufrió cuatro invasiones y conflictos bélicos de envergadura, una de las cuales -la invasión yanqui- tuvo funestas consecuencias. La situación política era de permanente inestabilidad (Argüello, 1983: 127). 
El segundo periodo estaba marcado por esfuerzos reformatorios identificados principalmente con la figura de Juárez, entorpecidos por la aventura imperial de un tal Maximiliano de Habsburgo, apoyado por bayonetas francesas desplegadas en su tiempo en casi todo el país. A partir del 1867 se abre un periodo de calma y reconstrucción nacional, lleno de ilusión de que por fin se cierra el turbulento devenir mexicano, permitiendo aterrizar a la nación recién conformada en una estabilidad y progreso socio-económico...

Creemos que ambos periodos abrieron escenario para dos tipos de articulación historiográfica. La primera, llamémosla patriótica con harto ingrediente nacionalista, trata el quehacer de historiador como una fuente forjadora de la identidad nacional, llena de orgullo de su pasado y aferrada a una simbología y referente ideológico bien definido, personalizado en el culto de la Virgen de Guadalupe. Este quehacer histórico ha sido cubierto por los innumerables escritos primero de Fray Servando Teresa de Mier y luego de Carlos María de Bustamante.

El segundo periodo permitió emerger a las monumentales figuras de la historiografía mexicana moderna, es decir, a Joaquín García Icazbalceta, Manuel Orozco y Berra y Francisco Paso y Troncoso'. Con ellos, la historiografía mexicana, sin perder su norte didáctico y cultural, alcanza el rigor científico ejemplar².

Por cierto, tenemos aquí algunos antecedentes relacionados con diferentes actividades de varios personajes ilustres que desde la segunda mitad del siglo XVIII y principios del XIX lograron acumular un enorme material para futuros historiadores stricto sensu, imbuidos en el pasado patrio. He aquí donde destacan dos personajes claves: el cosmógrafo de Carlos III Juan Bautista Muñoz y el gran coleccionista José Fernando Ramírez.

\section{Antecedentes (a): Juan Bautista Muñoz}

El primero, siendo relativamente joven, fue nombrado en 1770 cosmógrafo de Indias; luego, en 1779, recibió el encargo de escribir la historia del Nuevo Mundo y, acto seguido, como dice:

Favoreciendo mis ideas el Rey me autorizó con una cédula general fecha en 27 de Marzo de 1781 para disfrutar toda suerte de archivos, oficinas y bibliotecas, así del público como de comunidades

1 Obviamente la lista de arriba es absolutamente incompleta, pues hasta fines del siglo XIX hubo muchos más personajes de talla de los citados. Nos limitamos a aquellos nombres debido al principal propósito de nuestro artículo y para no abultar innecesariamente su contenido.

2 Comenta a propósito Eugenio del Hoyo Cabrera (Hoyo Cabrera, 1979: 231-232): «Las tres últimas décadas del siglo XIX ven florecer una pléyade de grandes historiadores, los más grandes que hemos tenido: verdaderos portentos de erudición y de capacidad de trabajo; infatigables y acuciosos investigadores, escritores elegantes, metódicos expositores de genial intuición, afortunados al trabajar en un campo hasta entonces virgen; descubridores de verdaderos tesoros documentales; hurgadores curiosos de ricos y viejos archivos y de las aún entonces ricas bibliotecas de los conventos novohispanos, nos dejaron magníficos acervos de documentación histórica, excelentes y bien construidas monografías y sabias interpretaciones; unos y otras, apoyos indispensables para cualquier trabajo histórico cuyo acontecer sea anterior a la Reforma. [...] hombres admirablemente dotados y de sólida formación humanística, equilibrados y ecuánimes, cuya búsqueda iba dirigida a los más variados asuntos: bibliografía, lingüística, etnografía, biografía, evangelización, descubrimientos y conquistas, historia precortesiana e historia novohispana, etc.». 
y particulares, recomendado mi comisión y persona de modo más eficaz. Diéronse las órdenes [...] para facilitar más y más la adquisición de materiales a la mayor comodidad y brevedad posible ${ }^{3}$.

Hay que reconocer un hecho universalmente conocido de que Muñoz cumplió sobremanera el encargo real, dando el gran impulso e inicio para el surgimiento del Archivo General de Indias en Sevilla. Como se menciona en una publicación (Pezuela, 1921) sobre la denominada Colección Muñoz: «Consta aquella voluminosa documentación de noventa y cinco tomos en folio, sin contar muchos ocupados por manuscritos históricos sobre diferentes regiones de América, África y Asia [...]». Tomando en cuenta la problemática que aquí nos ocupa, hay que mencionar dos cosas: el gran opúsculo escrito por Muñoz bajo el título Historia del Nuevo Mundo, editado en 1793 y rescatado por él y copiado el famoso manuscrito de Tolosa, donde después de más de doscientos años aparece la gran obra de Fray Bernardino de Sahagún Historia general de las cosas de Nueva España, un hecho que va a ocupar un relevante lugar en las actividades historiográficas de Bustamante, lo que mostraremos más adelante. Hay que subrayar que la Colección Muñoz se convirtió en un recurso primordial e indispensable de la moderna historiografía mexicana. Agreguemos aquí un hecho más relacionado a las actividades de Muñoz. Este el 18 de abril de 1794 tuvo una intervención en la sede de la Real Academia de la Historia en Madrid que trataba sobre el problema de la aparición de la Virgen de Guadalupe y su culto, presentando una visión totalmente crítica del supuesto portento. Dicha intervención aparece publicada en 1817 (Muñoz, 1817) y por cierto provoca airosa reacción de los aparicionistas, principalmente de Carlos María Bustamante (cf. infra).

\section{Antecedentes (b): José Fernando Ramírez}

Lo que hemos dicho sobre la Colección Muñoz podemos repetirlo en el caso del segundo coleccionista, José Fernando Ramírez, aunque en este caso hablamos del representante de una generación distinta. Uno de los autores considera que:

pertenece a la generación decimonónica que más ha aportado a la construcción de la Historia de México. Con Joaquín García Icazbalceta (1825-1894), Manuel Orozco y Berra (1816-1881), Francisco del Paso y Troncoso (1842-1916) y Juan Hernández y Dávalos (1827-1893) ha sentado las bases de la historia «rigurosa» y documentada (Sáenz Carrete, 2011: 100).

Recordemos que se desempeñó como director del Museo y la Biblioteca nacionales y tuvola mala suerte de apostar por el personajey gobierno de Maximiliano deHabsburgo. Por lotanto, después de la caída del II Imperio tuvo que exiliarse y a pesar de que pudo volver al país tras la promulgación de la ley de amnistía, murió en Bonn en 1871. Comenta Sáenz Carrete que tras su deceso:

[...] su biblioteca a la que llamó «Predilecta Mitad», padecería una serie de avatares. Su hijo José Hipólito Ramírez vendió la biblioteca de su padre al intelectual Alfredo Chavero, pero los problemas económicos obligaron a éste a venderla tres años más tarde a Manuel Fernández del

3 https://archive.org/details/historiadelnuev00mugoog/page/n15 [2-12-2019]. 
Castillo. El acervo en manos de Fernández del Castillo viajó a París, donde fue encargado al padre Agustín Fischer, quien convenció al primero para subastar los libros en Londres, en mayo de 1880 (Sáenz Carrete, 2011: 100).

De los aproximadamente 12 mil volúmenes se vendieron 934 títulos, principalmente manuscritos del siglo XVI, primeros impresos y crónicas ${ }^{4}$. No cabe la menor duda de que la colección de Ramírez, una parte en México y la otra, mucho más voluminosa, en el extranjero, constituía una tremendamente valiosa base para, entre otras cosas, investigaciones del pasado prehispánico y colonial de México. El mismo Ramírez nos dejó un amplio estudio de la vida y de la obra de Motolinía (Ramírez, 2004/1858: XLV-CLIII), abriendo asimismo el camino para el reconocimiento de este pasado como algo integral y relevante de la identidad mexicana, o -como dicen algunos- de la «mexicanidad»...

\section{El primer periodo de la historiografía mexicana del siglo XIX: Fray Servando de Mier y Carlos María Bustamante}

Recordemos que lo que predomina en el primer periodo después de 1810 es una búsqueda, organización y crítica de documentos (crítica aún incipiente y frecuentemente muy imperfecta) para elaborar una narración histórica caracterizada por su carácter cívico y uso político-ideológico, para que como resultado aparezca algún aceptable enfoque de la identidad nacional mexicana.

Se considera que un relevante impulso para el desarrollo de la historiografía mexicana se debe a un personaje, cuyo legado difícilmente se podría colocar en lo que constituye el quehacer habitual de un historiador. Se trata de la figura tanto controvertida como pintoresca y multicolor por sus múltiples aventuras de Fray Servando Teresa de Mier (1765-1827). Se indica que en lo que corresponde a los albores de la historiografía mexicana prevalece:

[...] la influencia del romanticismo y observamos en casi todos (los autores de la primera mitad del siglo XIX - J.A.) el predominio de una especie de inspiración mística, tumultuosa y profunda, que reemplaza la función que en la filosofía escolástica había desempeñado el elemento sobrenatural de la Revelación y que se explica por la consagración de la fantasía y del sentimiento, al lado de la fría razón, como órganos de conocimiento. En resumen, hallamos en los más distinguidos

4 Con el paso de los años, esas obras pasaron a formar parte de la Biblioteca Bancroft (Universidad de California, Estados Unidos), del Museo Británico y de la Biblioteca Nacional de España, mientras que en México parte de la colección se halla en los fondos reservados de la Biblioteca Nacional, así como de la Biblioteca Nacional de Antropología e Historia del INAH (Sáenz Carrete, 2011: 107). «Ramírez tuvo acceso a archivos franciscanos muy antiguos. Por ello, en el proceso de secularización de los conventos, pudo rescatar esta riqueza documental. Incluso se llega a decir que al contar con información privilegiada, pudo hacerse de manuscritos y libros importantes. Debe recordarse que el proceso de secularización fue en gran medida un saqueo de arte colonial, manuscritos y libros incunables pertenecientes a conventos y órdenes de clausura. Las autoridades que procedieron a la confiscación de estos materiales, en múltiples ocasiones, desconocían elvalory trascendencia delosmismos. Decualquier manera, debereconocersequeRamírezpudo rescatar un número importante de documentos y que los utilizó posteriormente para sus investigaciones. Jamás hubiera aceptado venderlos en el extranjero, ni siquiera por razones económicas» (Pezuela, 1921: 112). 
historiadores mexicanos de la primera mitad del siglo XIX, los mismos defectos y virtudes que se han señalado en los escritores coetáneos de otras latitudes (Colina, 1842: 43)5.

Sin duda, Fray Servando representa este enfoque, donde subyace un patriotismo exacerbado y nacionalismo que, con tan propia para él pasión, construye varias narraciones históricas frecuentemente muy lejanas de la realidad de los acontecimientos narrados.

Recordemos que Teresa de Mier entra en la historia de México pronunciando un sermón (1794), donde insinúa que las apariciones guadalupanas han sido ni más ni menos una impostura. Pero en esto hay algo más, pues decía:

Guadalupe no está pintada en la tilma de Juan Diego sino en la capa de Santo Tomé (conocido por los indios como Quetzalcóatl) y apóstol de este reino. Mil setecientos cincuenta años antes del presente, la imagen de Nuestra señora de Guadalupe ya era muy célebre y adorada por los indios aztecas que eran cristianos, en la cima plana de esta sierra del Tenayuca, donde le erigió templo y la colocó Santo Tomé» (Colina, 1942: 44).

Con el sermón pretendía demostrar que el culto guadalupano era prehispánico, al igual que el cristianismo, y por lo tanto no había motivos por los cuales agradecer a España, puesto que el imperio azteca era ya cristiano antes de 1519. Independientemente del ingrediente fantástico (para no decir fantasioso) de estas consideraciones que invocan ciertas especulaciones presentes en algunos cronistas del siglo XVI, lo que hace en el fondo Fray Servando es abrir un debate crucial para la naciente identidad mexicana en torno al culto de la Virgen de Guadalupe, que prontamente se convierte en un largo enfrentamiento entre los aparicionistas y antiaparicionistas (Colina, 1942: 43) ${ }^{6}$.

$\mathrm{El}$ «accidente guadalupano» causó que su protagonista fuese pronto excomulgado y desterrado a España. Mencionemos de paso que ha sido protagonista de innumerables escapatorias de diferentes prisiones y cárceles. Deja el hábito dominicano en 1802 (pasó al clero secular) y trata de una u otra manera de involucrarse en la futura lucha por la independencia de México. En 1811, invitado por Lucas Alamán, participa en las Cortes de Cádiz como miembro de la bancada americana, aunque muy lejos del perfil político e ideológico de Alamán. Fray Servando aparece en México recién en 1822 y a partir del 1823 como diputado electo participa en el segundo Congreso Constituyente. Entre sus obras figura «Historia de México desde los primeros movimientos que prepararon su independencia en el año de 1808 hasta la época presente», una publicación hecha por encargo del ex virrey Iturrigaray para convencer al rey que justamente aquel sería la persona más adecuada para restablecer el orden en Nueva España. Se considera que:

Fray Servando Teresa de Mier es uno de los testigos más conspicuos de las vicisitudes que trajo consigo la guerra de independencia y su impacto en la vida de los patriotas. Apologista de la

5 El autor agrega (ibíd.) que recién, en la segunda mitad del siglo XIX, surgen los personajes «[...] más dignos del título de historiadores por su genialidad y apego al método científico: Orozco y Berra, y García Icazbalceta». Observación que vamos a desarrollar más adelante.

6 Cf. Achmatowicz (2010), particularmente pp. 20-40. 
independencia con sus discursos encendidos, nos dejó en su Historia de la revolución de la Nueva España, antiguamente Anáhuac, o verdadero origen y causas de ella, con la relación de sus progresos hasta el presente año 1813, descripciones de sus innumerables prisiones y andanzas, donde justifica de una manera clara y vigorosa la independencia de nuestro país (Flores Torres, 2003: 13-14).

A propósito de la Historia de la revolución de la Nueva España..., una obra llena de pasión y narraciones exaltadas de poco asidero científico, donde: «[...] el orador sagrado, el fogoso polemista y patriota incólume se mezclan y confunden sin cesar [...]» (Colina, 1942: 44). No obstante, se considera que ha sido una obra de gran impacto para la visión popular de los acontecimientos que acompañaban al proceso independista mexicano. Agreguemos que dicho impacto se produjo también a través de la lectura de su «Apología o Memorias» y numerosos artículos periodísticos que dejó Teresa de Mier.

Al hablar de Carlos María de Bustamante (1774-1848) resulta imposible abarcar todas las actividades de este hombre tan multifacético. Fue un abogado, historiador, escritor, periodista, editor y político mexicano, continuamente involucrado en prácticamente todos los acontecimientos políticos y militares de su tiempo. La condición de polígrafo de Bustamante, sus dotes de periodista y editor incansable, le convierten en un caso, quizá único, en los anales de la cultura en México. Su bibliografía comprende 107 títulos. Fueron sus principales obras: Cuadro Histórico de la Revolución de la América Mejicana, Continuación del Cuadro Histórico, Apuntes para la historia del gobierno del general don Antonio López de Santa-Anna, El Nuevo Bernal Díaz del Castillo, o sea la historia de la invasión de los anglo-americanos en Méjico, Viaje a Toluca en 1834. Tratando de la obra de Bustamante se habla de unas 11 mil páginas de sus escritos.

En cuanto a sus aportes a la ciencia de la historia se puede decir:

De estilo confuso e incorrecto a menudo, pero pintoresco e ingenioso casi siempre; carente de espíritu crítico, lo que le hacía caer frecuentemente en contradicciones e inexactitudes; devoto de la causa de la Independencia, en cuya defensa llegó hasta falsear hechos y situaciones [sic]. Bustamante, a pesar de sus deficiencias, merece el cariño y agradecimiento de sus compatriotas por su acendrado patriotismo, y el de los eruditos por haber reunido rico y copioso material para la historia de México» (Colina, 1942: 45).

Una suerte de síntesis de esta figura tan controvertida nos la proporciona Óscar Flores Torres, quien dice que:

[...] a Carlos María de Bustamante le tocó conocer de cerca los incidentes de 1808 y saber de la detención de sus amigos; defendió la conjuración michoacana de 1809 y figuró después entre los partidarios de Morelos. Fue diputado al nacer la república [...] y editor de varias obras dedicadas a la historia antigua, como la de Sahagún, donde dejó innumerables comentarios en todo el transcurso de la obra, no del todo atinados. Si bien su obra escrita es compleja por su heterogeneidad (patética y sublime, a juicio de sus biógrafos) hay ejemplos de su obra donde se muestra claramente una tendencia historiográfica de exaltación a los héroes que otorgaron su vida (en pos de una idea) durante la guerra que terminó dando la independencia a México en 1821. En otras palabra, el inicio de una historia patria» (Flores Torres, 2003: 15). 
Dice Bustamante en su prólogo del editor de la Historia de las conquistas de Hernando Cortés (1826: 13)':

iOjalá mis afanes no sean inútiles y que la juventud mexicana entienda por la lectura de esta obra lo que fueron sus mayores, y que se esmere en contribuir a la felicidad de los restos de aquella gran familia que todavía vegeta en la miseria, reclama de justicia nuestra compasión y aún no percibe las ventajas del sistema liberal que hemos adoptado!

y sigue al final de su prólogo:

La suma del saber tanto en lo moral como en lo político, consiste, en que el hombre entienda de dónde viene, para dónde va, y de qué medios debe valerse para llegar felizmente al término para que fue criado (Bustamante, 1826: 13).

7 Es una edición muy particular, pues en ningún lugar el editor nos informa sobre el paradero del manuscrito en náhuatl, ni tampoco de quién es la traducción al castellano presente en esta edición. Se puede conjeturar sobre la base de lo manifiesto por Bustamante en la página IV que lo de Chimalpain era una traducción con comentarios o una historia de Gómara traducida y comentada por el «indio mexicano». Veamos algunos puntos claves de la presentación escrita por Bustamante que lo caracterizan muy bien como historiador y editor de las fuentes históricas:

a) Dice Bustamante en el «Prólogo del editor» que tuvo en sus manos un libro/manuscrito (i?) escrito por Juan Bautista de San Antón Muñon Chimalpain (1579-1660; indio originario de Amecameca y «descendiente de los antiguos Reyes de Texcoco»). Bustamante no especifica en qué idioma aparece este documento ¿en náhuatl o ya traducido al español? Tomando en cuenta las fechas podemos hablar únicamente de un manuscrito o una copia «de los manuscritos secretos» que se encontraba en la biblioteca del colegio de San Pedro y San Pablo en la época de la expulsión de los jesuitas.

b) p. III: Harto tiempo se pensaba que es una obra original de Chimalpain, incluso el mismo Bustamante siendo convencido de ello recibió de parte del congreso constituyente del estado de México 200 pesos para su impresión y reconoce que «[...] acabo de descubrir que este autor solamente la tradujo al mexicano de la que en castellano escribió Francisco López de Gómara por los años 1553, que se halla en el tomo segundo de los historiadores primitivos de las Indias occidentales, que tradujo en parte, y sacó a la luz D. Andrés González García» (en 1749). ¿Qué fue lo que «tradujo en parte» este último autor? ¿El manuscrito de Chimalpain?

c) p. IV: En cuanto a la obra de Gómara, Chimalpain: «[...] la hizo suya, y como tal la tradujo a la lengua mexicana $[\ldots] »$.

d) Sin embargo, resulta que lo de Chimalpain no era una simple traducción sino una traducción con comentarios y agregados, una Historia de la Conquista comentada.

e) En su prólogo Bustamante da prueba del desconocimiento de la historia de la llegada de la imprenta a México, ya que la adjudica al mismo Cortés quien, según él, trajolas prensas en 1532 (Icazbalceta, 1981:23-55).

f) p. XI-XII: Tenemos aquí un fragmento que nos revela costumbres bastante extravagantes de Bustamante como editor, quien advirtiendo que no todos los fragmentos del manuscrito publicado siendo importantes no se presentan con toda claridad, dice que: «[...] he puesto no pocas notas mías, y algunos apéndices tomados de Clavijero [sic] y de otros escritores inéditos que trataron cosas importantes como la muerte y bautismo de Mocthezuoma. Asimismo he presentado una larga disertación para la verdadera inteligencia del calendario mexicano que ha llamado la atención de los sabios de Europa, tanto por su artificio, como por los conocimientos astronómicos que tuvieron los mexicanos. Asimismo he presentado las tablas del calendario Tolteca que formó Boturini conformándolas con el romano, desde la creación del mundo hasta el año de $1821[\ldots] »$.

g) Por cierto, acto seguido justifica sus excesos editoriales diciendo lo que aparece en las dos citas presentadas arriba, en el texto principal. 
Hay que subrayar que resultó de trascendental importancia su labor de editor de libros antiguos, particularmente de obras históricas de época colonial, que por aquel entonces todavía estaban manuscritas y en parte olvidadas. He aquí donde surgen dos momentos en su vida como historiógrafo que nos interesan particularmente: la edición de la obra de Sahagún y la reivindicación de la causa aparicionista respecto al culto guadalupano. Como ya se ha mencionado, su empresa editorial más notable fue dar a conocer una obra precursora: Historia General de las Cosas de la Nueva España, escrita por fray Bernardino de Sahagún (1499-1590), publicada entre 1829 y $1830^{8}$, edición que por más de un siglo fue la única asequible a los estudiosos de la historia antigua de México9. Los interesantes detalles en torno a la llegada del manuscrito de Tolosa, la base de la edición de la obra maestra de Sahagún a México y luego a las manos de Bustamante nos lo cuenta con lujo de detalles Icazbalceta (1981: 361-362).

Lo de Sahagún es un ejemplo de los esfuerzos de un Bustamante historiógrafo y patriota; gracias a ellos han llegado a nosotros textos que hubieran podido perderse, aunque ciertamente esa tarea de editor conllevó modificaciones de títulos, interpolaciones, rectificaciones de textos y otros daños propios de la ligereza de este incansable historiador. Un ejemplo de todo esto va a ser la vuelta al tema tan relevante para la identidad mexicana como era y sigue siendo la aparición de la Virgen de Guadalupe.

En 1840 Bustamante edita una obra con muy extravagante título, la que en el fondo contenía la segunda versión del libro XII de la Historia... de Sahagún escrita por el franciscano en $1585^{10}$. Dice Icazbalceta:

[...] cuando Bustamante encontró en 1840 el verdadero libro XII corregido, persuadió al cabildo de la colegiata de Guadalupe, que el hallazgo destruía el argumento de Muñoz. [...] Cualesquiera creería después de esto que el P. Sahagún refería en este libro la historia de la aparición. Pues no dice palabra de ella y toda la disertación preliminar de Bustamante se reduce a sostener que están adulterados los escritos del P. Sahagún, puesto que después de concluido el libro XII, lo corrigió o escribió de nuevo, de donde saca la consecuencia que refirió la historia de la aparición y que los Españoles borraron el pasaje, por no convenirles que se publicara el favor tan distiguido que la Santísma Virgen había hecho a los Indios. ¿Pero quién busca crítica en Bustamante (Icazbalceta, 1971: XIX, nota 8)?

De hecho, como se puede observar en el título de este libro, Bustamante lo publica para desvirtuar aquella parte de la comunicación antiaparicionista de Muñoz que se sustentaba en un

8 Recordemos que lo que primero publica en 1829 Bustamante fue el libro XII de la gran obra de Sahagún, es decir, el que narra la historia de la conquista de México. Icazbalceta sugiere que la edición por separado del libro XII tuvo sus motivos en las contingencias políticas de aquel entonces, cuando tuvo lugar la punitiva expedición española... «Presentando a los lectores aquel lastimoso cuadro (de la conquista) quería que su recuerdo avivase el patriotismo de los mexicanos para rechazar la nueva invasión» (Icazbalceta, 1981: 363). 9 Fue editor también de la Historia de la provincia de la Compañía de Jesús de Nueva España, escrito por Francisco Javier Alegre, y de una de la Relaciones de Fernando de Alva Ixtlilxóchitl.

10 Todos los detalles correspondientes a la versión de 1585 de la Conquista de Cortés de Sahagún los desarrollamos en el primer tomo de nuestra monografía (versión electrónica) «Fray Bernardino de Sahagún - ensayos sobre su vida y obra». 
muy negativo testimonio contenido en la obra maestra de Sahagún. Bustamante se aferra a las siguientes palabras del franciscano en la versión enmendada del libro XII, referido a la Conquista: «se hicieron varios defectos y fue que algunas cosas se pusieron en la narración de esta conquista que fueron mal puestas; y otras se callaron que fueron mal calladas. Por esta causa, este año de 1585 enmendé este libro» (Sahagún, 1989: 147). Realmente en aquella versión no hay nada más. Lo único que habría que reconocer aquí fue el hecho de reabrir el debate sobre las apariciones guadalupanas, que prosiguió hasta bien entrado el siglo XX, con su punto culminante que han sido la beatificación y canonización del Indio Juan Diego.

Creemos que a pesar de todo tipo de críticas y reparos vale la pena citar aquí a su quizás más severo crítico, Icazbalceta, quien a propósito de la edición de la obra magna de Sahagún constata:

Es preciso hacer justicia a Bustamante por su empeño y actividad como editor. Sin fortuna, sin crédito, solicitando aquí y allí el favor de corporaciones y particulares, recogiendo por todas partes donativos, ya en dinero, ya en papel, y eso viviendo en época agitadísima, logró dar cima a la empresa en once meses (Icazbalceta, 1981:364).

Como una suerte de antípoda metodológico de Bustamante mencionemos brevemente a la figura de Lucas Alamán:

[...] el ideólogo [...] conservador más brillante de América hispana durante toda la primera mitad del siglo XIX fue un juez severo del estado manifiesto de anarquía y caos provocado en todos los territorios hispanoamericanos a consecuencia de las guerras de independencia a su posterior liberación política. Alamán concibió la guerra de independencia como el inicio de la destrucción del país y de la sociedad. De 1810 hasta su muerte (1853 - J.A.), el país no había recobrado la paz, la organización, ni el impulso económico esperado. [...] Mentor del partido conservador [...] empresario público y privado, fue también partidario de fortalecer las corporaciones militar y eclesiástica, únicas organizaciones -que a su juicio- daría rumbo, disciplina, orden y cohesión al país. [...] Al final de su vida, su pesimismo sobre el futuro de México, lo obligó a proponer y apoyar la dictadura militar, guiada más por administradores que por políticos (Flores Torres, 2003: 14-15).

Alamán nos dejó obras tales como: Disertaciones (1844-1849) e Historia de México (1849-1852). Hay una opinión bastante común que considera que era un autor que perfectamente manejaba los instrumentos de análisis de la contingencia histórica mexicana, sin embargo: «[...] sus hondos prejuicios de clase y su odio a la causa de la Independencia, no se le hubiesen impedido» (Colina, 1942: 46) ${ }^{11}$.

11 El autor invoca una larga cita del Padre Agustín Rivera (1884: 150-151), que aquí vamos a reproducir in extenso: «¿Quién era Alamán cuando escribía su Historia de la Revolución de la Independencia de México? Era el hijo de un español i de una realista de la nobleza española, descendiente de los marqueses de San Clemente; era el discípulo del Intendente Riaño, del Doctor Arechederreta i del Padre Fuentes; era el amigo de los virreyes Iturrigaray i Apodaca; era el acérrimo enemigo de Hidalgo, de Allende i del Grito de Independencia en 1810; era el realista diputado a Cortes; el defensor toda su vida del proyecto del Conde de Aranda, proyecto de aparente Independencia i de real dependencia de México de la Casa de Borbón o de 


\section{El segundo periodo de la historiografía mexicana del siglo XIX: Icazbalceta, Paso y Troncoso y Orozco y Berra}

A partir de la segunda mitad (más o menos) del siglo XIX se abre una carta nueva de la historiografía mexicana cuando junto con el surgimiento de la rigurosidad científica aparece, siendo parte relevante de la búsqueda de la autoconciencia nacional, el profundo interés por el pasado, tanto prehispánico como colonial. Esta revaloración del pasado mexicano aterriza en estudios verdaderamente científicos, basados en los fondos coloniales y los testimonios arqueológicos del mundo prehispánico. Comienza la clasificación de las grandes colecciones de cerámicas, diversas piezas arqueológicas y códices. El pasado mexicano se ventila a través de múltiples ramas de ciencia, tales como la sociología, lingüística y estadística, tratando de encontrar algún hilo conductor o bisagra histórica que relacionaría de modo alguno lo pretérito con lo presente.

Afortunadamente, los historiadores encontraron en las bibliotecas coloniales y en los añejos archivos nuevas fuentes para fundamentar su investigación. Se extiende la investigación científica de los periodos prehispánico y colonial (Ramírez, Orozco y Berra, García Icazbalceta, Chavero...). Es el momento cuando desaparecen grandes congregaciones religiosas y sus enormes y riquísimos archivos de sus bibliotecas conventuales pasan, sea a manos privadas, sea a las bibliotecas y archivos públicos. Por cierto, este proceso, como ya hemos mencionado en el caso de la Colección Ramírez, tuvo diferentes facetas y sufrió varios avatares que provocaron pérdidas completas o traspaso de la riqueza de fuentes nacionales mexicanas a las manos extranjeras (colecciones enormes en Estados Unidos, Inglaterra, Austria y España).

Consideramos que la figura clave y ejemplar de aquel periodo de la historiografía mexicana la constituye la brillante figura de Joaquín García Icazbalceta (1825-1894), del cual decía Menéndez y Pelayo sobre: «el gran maestro de toda erudición mexicana».

Su primer trabajo importante fue la traducción de la obra Historia de la conquista del Perú, escrita por William H. Prescott, a la que agregó notas y varios capítulos, publicándola hacia 1849 y 1850 . No obstante, podemos indicar que prácticamente toda su obra posterior se concentra en la creación de los fundamentos para el surgimiento de la historia de México como ciencia. Los documentos históricos que de diversas fuentes había obtenido los publicó, primero, en la Colección de documentos para la historia de México (2 vols. 1858, 1866) y, después, en la Nueva colección de documentos para la historia de México (5 vols. 1886-1892). En ambos casos agregó importantes noticias que los explican y aclaran.

Publicó, con prólogos que ilustran la vida del autor, la época y la naturaleza de la obra, algunos textos importantes: Carta de Hernán Cortés al emperador Carlos V (1855), Historia eclesiástica indiana, de fray Jerónimo de Mendieta (1870), Arte de la lengua maya, de fray Gabriel de San

otra potencia extranjera; era el que por una de esas peripecias que se ven en la política, había sido ministro de Victoria, a pesar de ser opuesto en ideas i muy desafecto a Victoria; era él que había sido ministro de Bustamante al tiempo de la muerte de Guerrero i procesado por esta muerte; era el redactor de El Tiempo; era, en fin, el borbonista hasta la muerte, el reverente depositario de la sagrada Majestad de los reyes, de la fidelidad de las colonias a la madre España, de la bondad del gobierno virreinal, i de todas las ideas i tradiciones de la monarquía española: ¿qué especie de Historia de la Revolución de Independencia iba a producir?» Lo citamos para poner de manifiesto diferentes avatares que sufría la historiografía mexicana en aquel entonces. 
Buenaventura (1888), Opúsculos inéditos, latinos y castellanos, de Francisco Javier Alegre (1889), Historia de los Indios de Nueva España de Fray Toribio de Motolinía (1858), el texto de El Conquistador anónimo (1858). Tradujo y publicó con el título México en 1554 los tres diálogos latinos que Francisco Cervantes de Salazar escribió y publicó sobre la ciudad de México en ese año. Tradujo asimismo Varios viajes de ingleses a la famosa provincia de México. La nueva colección de documentos para la historia de México (1889), conocida como Códice Franciscano-Siglo XVI, contiene un conjunto básico para la historia de la evangelización en el Nuevo Mundo.

Entre sus obras de carácter biográfico encontramos Don Fray Juan de Zumárraga, primer Obispo y Arzobispo de México, publicada en $1881^{12}$. La relevancia de este libro consiste en un fuerte rechazo de una suerte de leyenda negra sobre la actuación de los primeros evangelizadores en Nueva España respecto al acervo cultural indígena, donde se muestra a ellos, en su mayoría, junto con Zumárraga, franciscanos, como unos religiosos oscuros, fanáticos, carentes de cualquier cultura y preparación para llevar su tarea de cristianizar a los indios (Achmatowicz, 2008: 135-183). Icazbalceta introduce en su monografía un amplio estudio sobre este tema, poniendo de manifiesto que muchas acusaciones y opiniones sobre, entre otros, Zumárraga, no encuentran asidero en las fuentes correspondientes a aquella época (Icazbalceta, 1988b: t. II, 87-162). Además, se indican en la biografía del obispo sus enormes méritos relacionados con el único en su género, un experimento educacional que fue el famoso Real Colegio de Santa Cruz de Tlatelolco, donde los franciscanos (en varios periodos también Sahagún) reunieron hijos de los importantes indígenas y llevaron a cabo un proceso formativo y educacional de nivel comparable con los establecimientos universitarios en Europa. (Icazbalceta, 1988b: t. I, 286-301) Según las fuentes, era justamente Zumárraga quien había ideado la fundación del Colegio, contando con el apoyo del presidente de la II Audiencia en Nueva España, el obispo Sebastián Ramírez de Fuenleal y el primer virrey Antonio de Mendoza. Además, escribe Icazbalceta sobre el papel crucial de una empresa fundamental para la vida cultural en México, que fue la instalación de una imprenta prácticamente sobre los escombros de la vieja Tenochtitlan (Icazbalceta, 1988b: t. I, 302-304).

Sin duda se puede considerar como la obra magna de don Joaquín su Bibliografía Mexicana del siglo XVI (1886), la que en su época asombró a Menéndez y Pelayo. Realmente es la más amplia, ordenada, sistemática y documentada visión literaria del primer siglo de la época colonial de México en los campos de historia, literatura, bibliografía, filología y lenguas indígenas. La edición de 1981 contiene casi 600 páginas con 179 posiciones bibliográficas (desde 1539 hasta 1600) y además innumerables notas, observaciones (amplias en algunos casos y en otros pequeñas biografías y aclaraciones) de una erudición incomparable, siendo hasta la fecha la fuente principal y básica para el estudio de la cultura mexicana en el siglo XVI.

Hay que subrayar que entre las obras impresas presentadas en esta obra encontramos alrededor de 60 publicaciones de carácter lingüístico, directamente (artes, es decir, gramáticas, diccionarios) o indirectamente, o sea, diferentes obras relacionadas con procedimientos religiosos, ceremonias, ritos, oficios de sacramentos, etc., varias de ellas en diferentes idiomas

12 Disponemos de la edición en cuatro tomos de esta obra: Icazbalceta (1988b). 
indígenas de México. Justamente en esta obra Icazbalceta vuelve al tema de la llegada de la imprenta a México, dedicando a esta cuestión un amplio estudio introductorio titulado Introducción de la imprenta en México, donde con todo lujo de detalles y una documentación asombrosa pone de manifiesto los méritos al respecto tanto de Zumárraga como del virrey Mendoza (Icazbalceta, 1981: 23-55). En la obra comentada encontramos una enorme cantidad de notas de una relevancia enorme ${ }^{13}$. Sin embargo, consideramos que, desde la óptica de nuestra comunicación, se encuentra en esta obra maestra de Icazbalceta una verdadera joya, representada amplia y profundamente por la muy competente biografía de Bernardino de Sahagún, junto con el estudio absolutamente pionero de la tan complicada y hasta la fecha parcialmente oscura bibliografía de este fraile franciscano (Icazbalceta, 1981: 27-376) ${ }^{14}$. Se puede suponer que con este estudio se inician amplios y profundos estudios del acervo sahaguntiano, rescatando de su obra entre otras cosas la grandeza y riqueza de la cultura prehispánica en México. Sin duda esto tuvo un impacto relevante en aquellas partes de la identidad mexicana que miraban con creciente interés el pasado, tanto prehispánico como colonial.

No podemos aquí no mencionar a otra gran figura de la historiografía mexicana del siglo XIX, es decir, a Francisco del Paso y Troncoso. Dice Icazbalceta:

El Sr. D. Francisco del Paso y Troncoso, mi estimado amigo y colega, había reunido muchos materiales para la biografía y bibliografía de Fr. Bernardino de Sahagún, fruto de su inmensa lectura, aguda crítica y profundo conocimiento de nuestra historia. Es muy de sentirse que no concluyera la comenzada impresión de su trabajo, que dejó cuando supo que yo me ocupaba en el mismo asunto. Con una generosidad, rara en otros, pero muy propia de su invencible modestia, me cedió el puesto, sin considerar lo que el público y la ciencia perdían en el cambio. Hizo más, pues puso a mi disposición todos sus materiales, y después que los junté con los que por mi parte había adquirido, me favoreció con tantas noticias y disquisiciones interesantes, que después de tomar de ellas cuanto quise, y aún con las propias palabras del autor, me quedó la pena de no haber aprovechado sino una pequeña parte de aquella riqueza [...] pero entretanto, además de agradecerle públicamente su valiosa cooperación, es de justicia declarar, como declaro, que este artículo debería llevar más bien su nombre que el mío (Icazbalceta, 1981: 376).

Nos permitimos esta larga cita porque ilustra dos cosas. Primero, el profundo interés por la herencia sahaguntiana, compartida por la élite historiográfica de la segunda mitad del siglo XIX. Y segundo, muestra interesantes relaciones que se daban dentro de esta élite, donde en este contexto deberíamos incluir a Orozco de Berra. Lo que comenta Icazbalceta sobre su «amigo y colega» resulta para nada exagerado, pues en los años 1982-1983, gracias a las diligencias de Ignacio Bernal, gran histórico del siglo XX, aparecieron dos extensas cartas de Francisco

13 Por ejemplo: notas biográficas de Pedro de Gante, Cervantes Salazar, Freire, Alonso de la Vera Cruz, Domingo de la Asunción, Gilberti, Alonso de Molina, Juan Bautista; además de amplios artículos sobre los médicos de México en el siglo XVI o noticias de los autos de fe celebrados en México.

14 Vale la pena mencionar que también publica Icazbalceta algunos fragmentos desconocidos de la gran obra de Sahagún (1989: 376-387); aquí encontramos un fragmento intitulado Arte adivinatorio, donde Sahagún incorpora una muy fuerte crítica de Motolinía, sin mencionarlo de nombre. 
de Paso y Troncoso dirigidas a Icazbalceta ${ }^{15}$. Dichas cartas ponen de manifiesto que todo lo que comenta Icazbalceta era verdad, es más, las partes cruciales de su estudio en Bibliografía Mexicana del siglo XVI constituyen una transcripción casi literal de las observaciones de Paso y Troncoso ${ }^{16}$. Antes de proseguir con los aportes de Icazbalceta, creemos que podemos incluir en este lugar un corta nota justamente sobre su amigo.

Francisco del Paso y Troncoso (1842-1916) es sin duda una figura excepcional de la historiografía mexicana por varias razones. Primero hay que subrayar que al terminar sus estudios médicos decide no iniciar su carrera profesional como médico, sino que comienza a dedicarse por completo a la arqueología, lingüística, etnología, historia prehispánica y colonial; aunque vale la pena mencionar que en la década de 1880: «[...] estaba enfrascado en el estudio de la medicina y la botánica del México antiguo y ya apuntaba su interés hacia los códices» (Hernández de León-Portilla, 1997: 18). Hay que recordar en este contexto que era uno de los mejores nahuatlatos de su época. Sus méritos tienen que ver principalmente con el rescate y aporte de las fuentes para el estudio de diferentes periodos de la historia mexicana, aprovechados científicamente por varios autores que trabajaban sobre una síntesis del desarrollo de México, fuentes cuyo origen no siempre ha sido revelado en diferentes monografías. Ha sido un científico incansable, aunque sus proyectos más relevantes se quedaron inconclusos. La talla científica y de un hombre se refleja perfectamente en los testimonios que nos ha dejado su amigo Icazbalceta. Sus trabajos más importantes son: Descripción, historia y exposición del Códice Pictórico de los antiguos nahuas que se conserva en la Biblioteca de la Cámara de Diputados de París, antiguo Paláis Bourbon (1898); Papeles de Nueva España en varios volúmenes que contienen valiosísimos documentos y editados de 1905 a 1936, Epistolario de Nueva España en el cual póstumamente se recogieron documentos que van de 1505 a 1818, Índice de documentos de Nueva España existentes en el Archivo de Indias de Sevilla. Fue él quien reeditó (después de Bustamante, cuya edición se basaba en el Manuscrito de Tolosa) la obra de Sahagún que comenzó a imprimir en varios volúmenes a base del Códice Florentino. En Madrid, realizó la edición parcial en facsímile de los Códices matritenses en cinco volúmenes (1905-1907). Fue descubridor de la Crónica de Cervantes de Salazar, de la Historia de Baltazar de Obregón, de la Historia de Puebla de Fernández de Echeverría y Veytia, los Memoriales de Mota y Escobar y muchísimas otras más de gran mérito.

Volviendo a Icazbalceta recordemos que escribió una interesante Carta acerca del origen de la imagen de Nuestra Señora de Guadalupe de México (edición de 1896, dos años después de su muerte, obviamente sin su permiso), dirigida al Arzobispo de México Pelagio Antonio de Labastida y Dávalos. Ha sido una carta totalmente privada, escrita a petición del arzobispo de México, quien buscaba alguna autoridad historiográfica para opinar sobre un libro de José Antonio González «Santa María de Guadalupe, patrona de los mexicanos. La verdad sobre la aparición

15 La primera fue publicada en Estudios de Cultura Náhuatl, 1982, vol. 15, pp. 247-290, y la segunda también en Estudios de Cultura Náhuatl, 1983, v. 16, pp. 265-325. Ambas cartas fueron reimpresas en: Hernández de León Portilla (1997: 49-160).

16 Dice Ascensión Hernández de León-Portilla (1997: 19): «En realidad Icazbalceta utilizó magistralmente el material de Paso, al dotar de conexión estructural a las aisladas respuestas de don Francisco. El resultado fue un texto enriquecido que, después de un siglo, no lo sentimos anticuado». 
de la Virgen de Guadalupe». En principio don Joaquín se negó a opinar, sin embargo, cedió frente a la presión de la autoridad espiritual del arzobispo a quien tenía que obedecer.

El respeto absoluto de García Icazbalceta por la verdad hizo que, tan católico como era cuando estudió las fuentes sobre la apariciones guadalupanas de 1531, encontró que no había ninguna suficiente y fidedigna fuente que pudiera ofrecer algún soporte para el supuesto milagro. Lo pone de manifiesto en un documento de 70 puntos, donde esgrime argumentos profundos y bien elaborados. Lo que no quiere decir que su refutación lleve indicaciones indiscutibles, todo lo contrario. Hay que repetir que su carta confidencial aparece debido a un conjunto de circunstancias no del todo claras, siendo involucrados aquí José María de Agreda, Vicente de Paul Andrade y otros (Achmatowicz, 2010: 29, nota a pie de página 19). No obstante, sin querer, Icazbalceta con su carta aviva el debate en torno a las apariciones guadalupanas, siendo quizás Edmundo O’Gorman (2001) el más competente seguidor del enfoque antiaparicionista de Icazbalceta. Por supuesto no hace falta mencionar en este contexto que todo lo que tiene que ver con la Madonna de Tepeyac tiene que ver directa o indirectamente con la formación de la identidad y autoconciencia mexicana (Lafaye, 2002).

Agreguemos al final que dejó inconcluso un Vocabulario de mexicanismos, que publicó en 1905 su hijo Luis García Pimentel. Icazbalceta fue uno de los fundadores de la Academia Mexicana de la Lengua, donde ingresó el 25 de septiembre de 1875 y fue su primer Secretario (1875-1883) y su tercer Director (1883-1894). A él se debe la publicación de los primeros volúmenes de las Memorias de aquella Academia.

Terminando nuestra comunicación no podemos, siquiera de paso, no mencionar a Manuel Orozco y Berra (1816-1881), otro historiador de mucho prestigio, cuya obra tuvo un gran impacto en cuanto al rescate y la incorporación en la riqueza cultural de México de su pasado prehispánico. Fue sin duda uno de los pioneros y forjadores de la historiografía mexicana del siglo XIX, escritor muy prolífero y multidisciplinario. Entre sus maestros hay que mencionar a José Fernando Ramírez y Joaquín García Icazbalceta. Al referirse a él y a Icazbalceta Rafael de la Colina dice: «[...] ambos investigadores laboriosos, habilísimos críticos y eruditos historiógrafos, ajenos a la política militante y entregados por completo a la meditación y estudio» (Colina, 1942: 47). Es decir, tenemos aquí un profundo viraje en el quehacer de la historiografía mexicana, que toma el rumbo del enfoque decididamente científico, abandonando diferentes emociones y pasiones políticas, sociales y de la contingencia cotidiana. He aquí donde surge de a poco un material cada vez más rico para colocar el pensar sobre el pasado mexicano dentro de una narración que hubiera podido dejar huellas profundas en la autoconsciencia e identidad nacionales recién formándose.

Sin duda, junto con Orozco y Berra se ensancha el abanico de las investigaciones históricas, incorporando tales objetos de investigación como: valores religiosos, jurídicos, morales, artísticos, lingüísticos y económicos. El mismo Orozco y Berra, conforme con su época representaba, independientemente de la historiografía, diferentes quehaceres, siendo paleógrafo, geógrafo, periodista, lingüista, director del Archivo General de la Nación, encargado del Ministerio de Fomento y ministro de la Suprema Corte de Justicia. Hay que recordar también que salvó de la destrucción innumerables documentos, obras artísticas y monumentos históricos de México 
en su época histórica muy complicada y convulsionada. Justamente en los años 1853-1857 publica Documentos para la historia de México en veinte volúmenes. Hay que mencionar también que en 1864 publica su Geografía de las lenguas indígenas y carta etnográfica de México. En cuanto a su principal obra, «Historia antigua y de la conquista de Méxicas», mencionemos que fue una publicación monumental de casi 1200 páginas, editada en 4 tomos en 1880-1881 y dividida en cuatro partes:

1. Trata sobre cultura precolombina;

2. Sobre el hombre prehistórico en México;

3. Migraciones, conquistas y sucesos militares y políticos de los pueblos autóctonos, antes de la llegada de los españoles;

4. La Conquista;

Comenta Colina, a propósito de esta obra, que: «A través de los finos tamices de su crítica, los materiales de nuestra historia pre-virreinal se clasifican y depuran y, conforme a un bien trazado plan de lógica impecable, se ordenan y agrupan hasta formar un imperecedero monumento de las letras mexicanas» (Colina, 1942: 47). Observemos también que su Historia antigua... constituía durante varios decenios un referente indispensable no solamente para históricos profesionales sino también para un amplio público cada vez más interesado y orgulloso por el pasado mesoamericano de México.

\section{Conclusiones}

El pequeño recorrido por las figuras emblemáticas de la historiografía mexicana del siglo XIX que acabamos de presentar nos muestra que, independientemente de las profundas turbulencias políticas y sociales, incluidos los nefastos enfrentamientos con las intervenciones externas, México pudo contar con sus mejores intelectuales para poder aterrizar en el reconocimiento de su identidad nacional. Sin duda, aquella identidad, igual que en el caso de otras naciones, se forjaba en gran parte en relación al pasado mexicano, sea aquel inmediato, relacionado con la epopeya independentista, sea prehispánico que orgullosamente lleva lo mexicano al pedestal de las civilizaciones más brillantes de la humanidad, sea finalmente el pasado colonial cuando gradualmente se estaba formando la cultura criolla, fundamental para la autoconciencia nacional de los mexicanos. Justamente hemos tratado de mostrar el papel primordial en este proceso de los historiadores decimonónicos de la patria de Juárez, propósito, a pesar del espacio un poco reducido, que se habría logrado suficientemente. 


\section{Bibliografía}

У ACHMATOWICZ, Jerzy (2008). «Fray Juan de Zumárraga ¿Fanático destructor o benefactor? (Equipaje intelectual y espiritual versus la "leyenda negra" de la evangelización franciscana en la Nueva España)». Estudios Latinoamericanos, 28, pp. 135-183.

У ACHMATOwiCz, Jerzy (2010). Nican Mopohua - główne źródło studiów nad objawieniami guadalupańskimi w Meksyku w 1531. Wrocław: Atut.

У ARGÜELlo, Gilberto (1983). «El primer medio siglo de la vida independiente». In: Enrique Semo (coord.). México un pueblo en la historia. Universidad Autónoma de Puebla: Editorial Nueva Imagen, t. 2, pp. 21-147.

У Bustamante, Carlos María (1840). La aparición de la Nuestra Señora de Guadalupe de México. Comprobada con la refutación del argumento negativo que presenta D. Juan Bautista Muñoz, fundándose en el testimonio del P. Fr. Bernardino Sahagún; o sea: Historia Original de este escritor, que altera la publicada en 1529 en el equivocado concepto de ser única y original de dicho autor. México: Impreso por Ignacio Cumplido.

\ Bustamante, Carlos María (ed. 1826). Historia de las conquistas de Hernando Cortés escrita en español por Francisco López de Gómara, traducida al mexicano y aprobada por verdadera por D. Juan Bautista de San Anton Muñon Chimalpain Quauhtlehuanitzin, indio mexicano. México: Imprenta de la testamentaria de Ontiveros.

ע COLINA, Rafael (1942). «Historiadores Mexicanos del siglo XIX». Revista Hispánica Moderna, 8.1-2, pp. 43-48.

У FLORES TORRES, Óscar (selección, presentación y notas) (2003). Historiadores de México siglo XIX. México D.F.: Ed. Trillas.

У GARCÍA ICAZBALCETA, Joaquín (1981). Bibliografía mexicana del siglo XVI. México: FCE. [La primera edición en 1886].

У GARCía ICAZBALCETA, Joaquín (1988a). Biografías, Estudios. México: Editorial Porrúa.

๖ GARCÍA ICAZBALCETA, Joaquín (1988b). Don Fray Juan de Zumárraga, primer Obispo y Arzobispo de México. 4 vols. México D.F.: Editorial Porrúa.

ע García ICAzbalceta, Joaquín (2004). Documentos para la Historia de México. Reimpreso de la edición del 1858. México: Biblioteca Porrúa.

У HERNÁNDEZ DE LEÓN-PORTILLA, Ascención (ed. e intr.) (1997). Bernardino de Sahagún - Diez estudios acerca de su obra. México D.F.: FdCE. HOYO CABRERA, Eugenio (1979). «Historiografía mexicana». Sobretiro de Humánitas, 20, Universidad de Nuevo León, pp. 1-9.

ע LAFAYE, Jacques (2002). Quetzalcóatl y Guadalupe, la formación de la conciencia nacional. México D.F.: FdCE.

ע MUÑoz, Juan Bautista (1817). «Memoria sobre las apariciones y el culto de Nuestra Señora de Guadalupe de México, leída en la Real Academia de Historia por su individuo supernumerario don Juan Bautista Muñoz». In: Memorias de la Real Academia de la Historia, t. V, Madrid, pp. 205-224. o'GORMAN, Edmundo (2001). Destierro de sombras. México D.F.: UNAM.

y ORozco y berra, Manuel (1880-1881). Historia antigua y de la Conquista de México. 2 vols. México: Tipografía de Gonzalo A. Esteva.

У PEZuela, Jacobo (1921). «La Colección Muñoz en la Real Academia de la Historia». Boletín de la Real Academia de la Historia, t. 79, Alicante. http://www.cervantesvirtual.com/nd/ark:/59851/bmc029b6 [2-12-2019]. 
y RAMírez, José F. (2004/1858). «Noticias de la vida y escritos de Motolinía». In: Joaquín García Icazbalceta. Colección de documentos para la historia de México. México D.F.: Porrúa, t. I, pp. XLV-CLIII.

\ RIVERA, Agustín (1884). Principios críticos sobre el Virreinato de la Nueva España y sobre la Revolución de la Independencia.México:SanJuandeLosLagos.http://cdigital.dgb.uanl.mx/la/1080017583_C/1080017583_ T1/1080017583.PDF [01-12-2019].

ע SÁENZ CARRETE, Erasmo (2011). «José Fernando Ramírez: su último exilio europeo y la suerte de su última biblioteca». Signos Históricos, 25 (enero-junio), pp. 100-135.

У SAHAGÚN, Fray Bernardino (1989). Conquest of New Spain, 1585 Revision, Reproductions of the Boston Public Library Manuscript and the Carlos Maria Bustamante 1840 edition, translated by Howard F. Cline, Edited with an introduction and notes by S.L. Cline. Salt Lake City: University of Utah Press.

\section{Jerzy Achmatowicz}

Instytut Filologii Romańskiej

Uniwersytet Wrocławski

Pl. Biskupa Nankiera 4

50-140 WROCEAW

Polonia 